\title{
Mars rock samples condemned to quarantine
}

\section{Tony Reichhardt, Washington}

As if collecting rocks from the surface of Mars and returning them to Earth weren't challenge enough, a panel of scientists is recommending that NASA design and build a unique quarantine facility to ensure that any organisms in the martian samples don't contaminate the terrestrial environment.

Quarantine of martian rocks has long been considered a requirement for any mission to collect samples. But last week's report by the National Academy of Sciences' Committee on Planetary and Lunar Exploration (COMPLEX) was the most detailed look yet at how such a facility should be designed.

The panel, chaired by John Wood of the Harvard-Smithsonian Center for Astrophysics, says that NASA should start working on the problem as soon as possible. The space agency currently plans to bring martian samples back to Earth by about 2014 .

The chance of finding viable organisms in a martian rock is extremely remote, but scientists have nonetheless advised utmost caution in handling returned samples.

The report recommends that the Mars quarantine lab apply the most stringent level of control, Biosafety Level 4 (BSL-4), which is typically used for germ-warfare agents or pathogens such as the Ebola virus.

The simplest solution would be to build the new facility next to an existing BSL-4 lab, such as those at the Centers for Disease Control and Prevention in Atlanta and at the US Army Medical Research Institute of Infectious Diseases at Fort Detrick, Maryland. Another BSL-4 facility is being built at the
University of Texas at Galveston, near NASA's Johnson Space Center, which houses the Moon rocks from the Apollo missions.

The new facility, however, will have to function both to keep contamination out and to contain pathogens. The usual way to accomplish one of these is to use rooms with different atmospheric pressures, so that leakage is forced in the desired direction. But no one has built a lab that does both.

The COMPLEX panel did not discuss engineering details, but Wood is confident that "it can be done". The price tag is largely guesswork, but based on the $\$ 8$ million it cost NASA to build a laboratory for the Moon rocks in the 1960s, and adjusting for inflation, Wood estimates that the facility could be built for around $\$ 32$ million. NASA plans to spend $\$ 427$ million this year alone on its Mars exploration programme.

The panel recommends that the facility be kept as simple as possible, and that inves- tigation of the samples take place elsewhere. So the other challenge facing the lab's designers is how to sterilize samples for release without destroying any biological evidence.

The recommended method for sterilizing samples is gamma-irradiation and dry heat. But heating the samples would remove water and destroy organic compounds. The answer may be to extract compounds first, sterilize them, and send them out for study.

But the panel admits that more research is needed. "Unfortunately the recommended techniques of sterilization damage organic compounds to some extent," it says. "It is important that studies be carried out to enlarge our knowledge in this area."

In the unlikely event that the rocks contain unambiguous signs of life, they would stay in the quarantine facility until a research strategy could be formulated. But that possibility is so remote that COMPLEX did not provide a detailed plan for it.

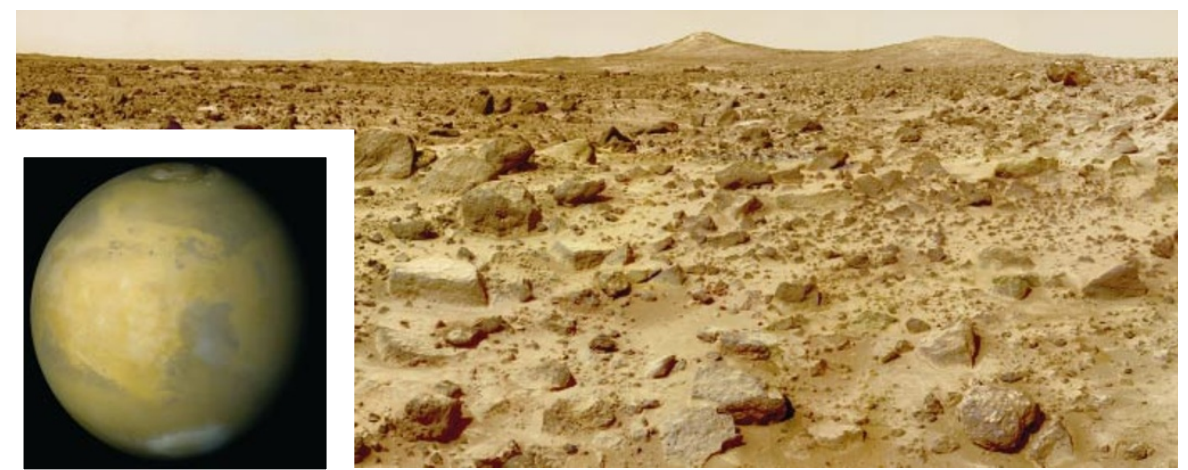

Beware of the martians: rock samples could be given the same biohazard status as germ weapons.

\section{Aurora project set to pave way for human space flight}

\section{Alison Abbott, Munich}

The European Space Agency (ESA) is planning a programme that will enable it to maintain an interest in human space flight, once the construction of the International Space Station is completed in around 2005.

The programme, called Aurora, won support at a meeting of representatives of ESA member states last week. It would probably involve an initial series of robotic missions - mainly to asteroids, Mars and the Moon - followed by human missions.

An important branch of Aurora would develop technologies for human space travel. Research would address soft spacecraft landings, and solar-electric and nuclear propulsion systems to allow astronauts to travel faster - thereby reducing their exposure to cosmic radiation. Physical and psychological health research programmes for astronauts would also be included.
But another part of Aurora would support science, including exobiology the study of the origin, evolution and distribution of life in the Universe.

There is no doubt about the scientific community's enthusiasm for the Aurora concept, ESA officials say. The agency put out a four-week call for ideas for the proposal in February and received nearly 300 submissions - "ten times the number we normally attract," says Franco Ongaro of ESA's Advanced Concepts and Studies Office.

"This is just the right time to ride the wave of interest in exobiology," says Paul Murdin of the British National Space Centre, the United Kingdom's delegate to the Aurora committee. Murdin says the discipline is attracting a whole new community of researchers.

ESA will ask its governing council, which meets this month, to support a 40-million- euro (US\$34 million) three-year preparatory phase for Aurora, starting next year. ESA member governments will probably scale this down, officials say. Each member state will be able to choose whether or not to participate in the programme, although it seems likely that most of the agency's 15 member nations will sign up to it.

Aurora would be managed separately from ESA's existing programmes for science and human space flight. There is concern that it could threaten funding for these programmes, which is mandatory for all ESA members. But Murdin says that it would complement existing programmes and enable ESA to develop the technologies needed for human space flight.

Supporters of Aurora envisage that it could eventually match ESA's existing science programme in size, with an annual budget of 200 million-300 million euros. 